For personal use only. Not to be reproduced without permission of the publisher (editorial@gabi-journal.net)

\title{
Generic medicines entry into the Malaysian pharmaceutical market
}

\author{
Omotayo Fatokun, PhD; Professor Mohamed Izham Mohamed Ibrahim, PhD; Professor Mohamed Azmi \\ Hassali, PhD
}

There are major barriers to generic medicine development and market entry in Malaysia. This mixed method study recommends several strategies to increase uptake.

\section{Keywords: Generic medicines, Malaysia, market entry, patent, pharmaceutical market}

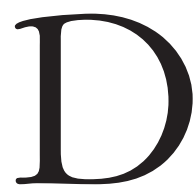

ue to the rising costs of pharmaceuticals and a prevailing economic crisis, the availability of generic equivalents of trademark innovator medicines has become crucial to the Malaysian healthcare system. In 2003, Malaysia became the first country in Asia to issue a compulsory licence for the importation of generic versions of patented antiretroviral medicines, following the adoption of the World Trade Organization (WTO) Doha declaration on the Trade-Related Aspects of Intellectual Property Rights (TRIPS) agreement and public health. [1, 2]. This action was taken to increase access to affordable antiretroviral medicines, patented forms of which were highly priced. As a result of the licence, the average treatment costs per HIV-infected patient per month in public hospitals declined by up to $83 \%$ and there were widespread reductions in the prices of innovator patented antiretroviral products $[1,3]$. Nevertheless, issues surrounding pharmaceutical patents mean medicine accessibility and generics availability continue to be a challenge in Malaysia [2].

The summary of the findings from a study on generic medicines entry into the Malaysian pharmaceutical market is presented in this paper. The determinants and characteristics of generic medicines entry following the patent expiration of innovator drug products in Malaysia were investigated. The sources of data used for the work included 22 policy documents, a survey of 13 key informants, a cross-sectional questionnaire of 14 generic medicines manufacturing industries, and panel data analysis of the 12 best-selling single entity prescription drug products that experienced loss of patent protection and subsequent generics entry in Malaysia between January 2001 and December 2009 [4].

The study began with analysis of policy documents, followed by semi-structured interview and qualitative questionnaire survey. The policy analysis included analysis of policy content, outputs and processes. The documents were restricted to publicly available and nationally-applicable official documents from government sources (print or Internet-based). These documents include laws, regulations, rules, policies, administrative orders, directives, guidelines, reports and other documented statements issued by the government, ministries, departments and agencies that were intended to directly or indirectly affect the production, distribution, prescribing, dispensing and the use of medicines in
Malaysia. The key informants' survey consisted of semi-structured interviews and self-completed qualitative questionnaire. The potential key informants were selected using a purposive nonprobabilistic sampling, i.e. on the basis of their key position, professional expertise and good knowledge of the generic medicines environment in Malaysia. The 13 key informants were from seven organizations, i.e. the Malaysian Organization of Pharmaceutical Industries, generic medicines importers, Malaysian Medical Association, Malaysian Pharmaceutical Society, Federation of Malaysia Consumers Associations, Malaysian Pharmaceutical Services Divisions, and National Pharmaceutical Control Bureau. Cross-sectional national surveys of a self-completed questionnaire were used among generic drug manufacturers. The final study design was the panel data analysis on 'best-selling' single entity prescription International Nonproprietary Name (INN) drug products that lost patent protection and experienced subsequent generics entry. The drugs selected in this study were based on the empirical justification that post-patent entry of generic medicines is driven by the sales value of the patented drug molecule before patent expiration. Initially, 64 INN drug products were selected and screened to determine their registration status. The registration status of the drug products were obtained from the list of approved products and the drug products registration database of the Malaysian National Pharmaceutical Control Bureau.

Fourteen categories of policies and regulatory measures with varying effects on generics entry in Malaysia were identified. The major factors driving generics development and market entry in Malaysia were the prepatent expiration market value of innovator products, the cost of generics development and approval, and compatibility with pharmaceutical firms' existing product ranges. The innovator product's prepatent expiration market value was also a significant entry driver, but more so for domestic generics firms than export-oriented companies.

The major barriers to generic medicine development and market entry identified were patent clustering by innovator firms and the earlier market entry of imported generics. Government policies and regulations were perceived by respondents to be fairly effective in promoting generic medicines in Malaysia. The majority of respondents were dissatisfied with generics prescribing and generic medicines understanding among healthcare professionals, but satisfied with generics dispensing.

Author for correspondence: Professor Mohamed Izham Mohamed Ibrahim, PhD, Professor of Social and Administrative Pharmacy, College of Pharmacy, Qatar University, Al Tarfa, PO Box 2713, Doha, Qatar

Submitted: 25 October 2016; Revised: 15 November 2016; Accepted: 21 November 2016; Published online first: 28 November 2016 
For the 12 best-selling prescription drug products, a total of 154 generics entries occurred over the eight-year period under study. The highest proportion of the sample belong to the cardiovascular class of drugs, followed in equal proportions by respiratory and nervous system drug products, which reflects the burden of disease among the Malaysian population. The occurrence of market entry for these drugs is characterized by a sequential quadratic curvilinear trend. The time to entry of generics was significantly longer than the hypothesized time to entry of one day following the basic patent expiration of an innovator product. This hypothesis is based on the TRIPScompliant regulatory exception provision (also known as the early working exception or Bolar provision), and is used to enable the development of generic medicines before innovator product patent expiration [5, 6]. Competition among 28 offpatent drugs, the majority of which had been on the market for several years, showed that increased generics availability reduces drug prices in the off-patent pharmaceutical market. These findings illustrate the importance of the unhindered entry of generic medicines following the patent expiration of innovator drug products.

In sum, the presence of a variety of government policies have had varying effects on the entry of generic medicines to the Malaysian pharmaceutical market. These policies are those related to intellectual property rights; medicines regulation and registration; pharmaceutical pricing and competition; and the demand-side policies measures on generics prescribing, dispensing and consumptions. Market entry was found to be determined by the prepatent sales value of innovator products, the cost of generics development, market entry competition and the existence of patent-related entry barriers. The pattern of generics entry was characterized by a sequential curvilinear trend, and the time to generics entry was found to be significantly delayed beyond the expiration of the equivalent innovator product's basic patent.

To improve generic medicines entry into the Malaysian pharmaceutical market, it is recommended to: (i) increase coherence between intellectual property rights and health policies; (ii) improve the patent administration system and ensure strict adherence to the patentability criteria of novelty; (iii) discourage any linkage between drug marketing approval and patents, including requests for listing of patent information with the drug regulatory authority; (iv) make trade-related policy coherent with regard to market entry of imported generic medicines vis-a-vis locally produced generic medicines; (v) enhance domestic capacity in bioequivalence testing and manufacturing to ensure more cost-efficient production of generic medicines; (vi) implement policies relating to generic medicines consistently across both the public and private sectors of the Malaysian healthcare system; and (vii) increase education and awareness of generic medicines among healthcare professionals and the public to promote generics prescribing, dispensing and consumption [7, 8].

\section{Competing interests: None.}

Provenance and peer review: Not commissioned; internally peer reviewed.

\section{Authors}

Assistant Professor Omotayo Fatokun, PhD

Department of Clinical Pharmacy, Faculty of Pharmaceutical Sciences, UCSI University, No. 1 Jalan Menara Gading, Cheras, 56000 Kuala Lumpur, Malaysia

Professor Mohamed Izham Mohamed Ibrahim, PhD

Professor of Social and Administrative Pharmacy

College of Pharmacy, Qatar University, Al Tarfa, PO Box 2713, Doha, Qatar

Professor Mohamed Azmi Hassali, PhD

Discipline of Social and Administrative Pharmacy, School of Pharmaceutical Sciences, Universiti Sains Malaysia, 11800 Minden, Penang, Malaysia

\section{References}

1. Ling CY. Malaysia's experience in increasing access to antiretroviral drugs: exercising the 'government use' option. Penang: Third World Network; 2006.

2. Smith RD, et al. Trade, TRIPS, and pharmaceuticals. Lancet. 2009;373(9664):684-91.

3. World Health Organization. Commission on Intellectual Property Rights, Innovation and Public Health (CIPIH). Musungu SF, Oh C. The use of flexibilities in TRIPS by developing countries: can they promote access to medicines? 2006 [homepage on the Internet]. [cited 2016 Nov 15]. Available from: http://www. who.int/intellectualproperty/studies/TRIPSFLEXI.pdf

4. Fatokun O. Assessment of policies, determinants and characteristics of generic medicines entry into the Malaysian pharmaceutical market [dissertation]. Universiti Sains Malaysia; 2014.

5. De Joncheere K, Rietveld AH, Huttin C. Experiences with generics. Int J Risk Saf Med. 2002;15(1):101-9.

6. European Commission. Pharmaceutical sector inquiry final report [homepage on the Internet]. [cited 2016 Nov 15]. Available from: http://ec.europa.eu/ competition/sectors/pharmaceuticals/inquiry/staff_working_paper_part1.pdf

7. Kaplan WA, Wirtz VJ, Stephens P. The market dynamics of generic medicines in the private sector of 19 low and middle income countries between 2001 and 2011: a descriptive time series analysis. PLoS One. 2013;8(9):e74399.

8. Benjamin D, Swartz M, Forman L. The impact of evidence-based education on prescribing in a psychiatry residency. J Psychiatr Pract. 2011;17(2):110-7. DOI: $10.5639 /$ gabij.2016.0504.046

Copyright (C) 2016 Pro Pharma Communications International 